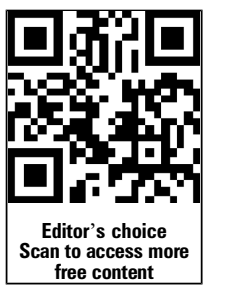

- Additional material is published online only. To view please visit the journal online (http://dx.doi.org/10.1136/ jclinpath-2014-202561).

${ }^{1}$ Department of Pathology, Harvard Medical School, Boston, Massachusetts, USA ${ }^{2}$ 2nd Department of Internal Medicine, Semmelweis University, Budapest, Hungary ${ }^{3}$ Molecular Medicine Research Unit, Hungarian Academy of Sciences, Budapest, Hungary

\section{Correspondence to}

Gabor Valcz, 2nd Department of Internal Medicine,

Szentkirályi u. 46, Budapest $\mathrm{H}-1088$, Hungary; valczg@yahoo.com

Received 14 July 2014 Accepted 28 July 2014 Published Online First 18 August 2014

\title{
Importance of carcinoma-associated fibroblast-derived proteins in clinical oncology
}

\author{
Gabor Valcz, ${ }_{1}^{1}$ Ferenc Sipos, ${ }^{2}$ Zsolt Tulassay, ${ }^{3}$ Bela Molnar, ${ }^{3}$ Yukako Yagi ${ }^{1}$
}

\begin{abstract}
Carcinoma-associated fibroblast (CAF) as prominent cell type of the tumour microenvironment has complex interaction with both the cancer cells and other nonneoplastic surrounding cells. The CAF-derived regulators and extracellular matrix proteins can support cancer progression by providing a protective microenvironment for the cancer cells via reduction of chemotherapy sensitivity. On the other hand, these proteins may act as powerful prognostic markers as well as potential targets of anticancer therapy. In this review, we summarise the clinical importance of the major CAF-derived signals influencing tumour behaviour and determining the outcome of chemotherapy.
\end{abstract}

\section{INTRODUCTION}

\section{Carcinoma-associated fibroblasts in tumour stroma}

In the process of tumour formation, the normal microenvironment 'niche' changes to an altered (ie, reactive or desmoplastic) stroma which is composed of non-malignant supporting cells (ie, blood vessels, infiltrating inflammatory cells and blast-like cells). ${ }^{1} 2$ This altered microenvironment functions as a collaborative partner in the process of tumourigenesis by influencing the homeostasis of cancer cells via paracrine regulators (eg, growth factors, cytokines and chemokines) and exosomes containing nucleic acids. ${ }^{13-5}$ Cancer associated fibroblasts (CAFs), prominent stromal elements in most types of human carcinomas, are $\alpha$-smooth muscle actin positive, spindle-shaped, blast-like cells. Differentiation of CAFs from other cell types, such as local fibroblasts, hepatic stellate cells, mesenchymal stem cells, endothelial and epithelial cells, is mainly mediated by transforming growth factor- $\beta 1$ (TGF- $\beta 1$ ), but other factors, such as growth hormones (ie, epidermal growth factor (EGF), fibroblast growth factor (FGF) and platelet-derived growth factor (PDGF)), chemokines, epigenetic regulators and oxidative stress also may play a role in CAF differentiation. $^{4} \quad 6 \quad 7$ CAFs, phenotypically, closely resemble normal myofibroblasts, but they express specific markers (ie, fibroblast activation protein (FAP), fibroblast-specific protein 1, neuronglial antigen-2, vimentin, Thy-1, tenascin (TN)-C, periostin (POSTN), palladin or podoplanin (PDPN)) and display an increased proliferation and migratory behaviour in vitro. ${ }^{8} 9$ CAFs produce and secrete various extracellular matrix (ECM) proteins (ie, collagens I, III, IV), proteoglycans (ie, fibronectin, laminin, TN), chemokines (eg, CXCL and CCL), cytokines (eg, interleukin (IL)-6 and IL-8) and other tumour-promoting factors which affect vascularisation (ie, PDGF, vascular endothelial growth factor (VEGF), stromal-derived factor-1 (SDF-1), matrix metalloproteinase (MMPs)), proliferation capacity, tumour cell invasiveness and survival (ie, TGF- $\beta$, EGF, hepatocyte growth factor (HGF) or FGF). ${ }^{19-11}$

Regarding anticancer therapy, the frequency of genetic mutations in CAFs is one of the most important issues. Cells with genetic stability may be less prone to escape or resistance to chemotherapy than those with genomic instability. ${ }^{12}$ Several studies demonstrated that high percentage of CAFs undergo genetic alterations, such as loss of heterozygosity or mutation of tumour suppressor genes (ie, phosphatase and tensin homolog and P53). ${ }^{13-16}$ The theory of genetic coevolution of CAF and the neighbouring cells (ie, random mutation of CAF generated independently from neoplastic epithelial cells that may support tumour progression) is under debate due to the potential artefacts caused by the analytical methods used for the identification of these genetic alterations. ${ }^{17}$ Other groups described that the somatic mutations of CAFs are found to be extremely rare and are unlikely to be responsible for their stable cancer-promoting attributes. ${ }^{18} 19$

In this short review, we discuss those CAFderived proteins which (1) may have an important role in the development of environment-mediated drug resistance, (2) may act as powerful prognostic markers and (3) may be promising targets of anticancer therapy.

\section{Relation of CAFs to microenvironment-mediated drug resistance}

Emerging data suggests that several factors of the tumour microenvironment play a critical role in determining therapy response. ${ }^{10}$ CAF-derived factors may contribute to the development of a protective milieu via influencing the following: (1) cell-cell/cell-matrix interactions, (2) cancer cell survival, (3) interstitial fluid pressure (IFP) within the tumour and (4) suppression of antitumoural immune responses. $^{2} 20$

Cell adhesion-mediated drug resistance (CAM-DR) is mediated by the adhesion of tumour cells to stromal fibroblasts or to ECM components. ${ }^{21}$ Physical contact between host fibroblasts and tumour cells (eg, melanoma and non-small cell lung cancer (NSCLC) cells) supports tumour cell survival via activation of antiapoptotic pathways or inducing epithelial-to-mesenchymal transition (EMT). ${ }^{10}$ 22-24 EMT-originated blastoid cells can acquisite cancer stem cell-like traits and drug resistance against conventional chemotherapeutics (eg, taxol, vincristine, oxaliplatin or gemcitabine), as well as anti-EGFR therapy. ${ }^{7} 24$ Adhesion of cancer cells to ECM proteins, such as CAF-derived 
laminin, collagen, fibronectin and POSTN also results in CAM-DR. ${ }^{10} 20$ These proteins can bind to integrin receptors (eg, $\alpha 1-\alpha 6 \beta 1$ and $\alpha v \beta 5$ ) located on the surface of tumour cells and cause protection against drug-induced apoptosis via activation of the phosphatidylinositide 3-kinase (PI3K)/AKT pathway, which inhibits the release of drug-induced apoptotic factors, like cytochrome-c. $^{26} 27$

CAF-derived soluble regulators, such as hormones, chemokines and cytokines are also able to mediate the therapy resistance in different ways. Activation of receptors by prostaglandin E2 $\left(\mathrm{PGE}_{2}\right)$, sphingosine-1-phosphate and PDGF-C ligand promotes tumour cell survival by activation of PI3K/AKT and Hedgehog signals in vitro. ${ }^{20}$ DNA damage-induced nuclear factor- $\kappa \mathrm{B}(\mathrm{NF}-\kappa \mathrm{B})$ dependent wingless-type MMTV integration site family member 16B (WNT16B) protein expression in fibroblast can lead to mitoxantron therapy resistance in prostate cancer cells through $\mathrm{T}$ cell factor/lymphoid enhancer binding factor activation. ${ }^{28}$

IFP and transvascular transport of anticancer drugs also may influence the success of chemotherapy. Inhibition of CAF-derived VEGF, PDGF or their receptors results in lower IFP within tumours, hence, improves chemotherapy efficacy. ${ }^{29}$ ${ }^{30}$ For example, treatment with anti-PDGF antibody may regulate IFP by the relaxation of cells constituting connective tissues, integrin-mediated contacts with ECM fibres, or ECM rebuilding into a less dense structure. ${ }^{29}$

CAFs are also involved in tumour-mediated immunosuppression by the expression of immunomodulating ECM proteins, such as $\mathrm{TN}-\mathrm{C}$, inhibiting the migration of monocytes and adhesion of $\mathrm{T}$ lymphocytes to fibronectin, and thrombospondin-1, regulating cellular phenotype of antigen-presenting cells/APCs and T cells. ${ }^{31} 32$ CAF-derived chemokines, such as monocyte chemotactic protein-1/CCL2, modulate monocyte migration and release of IL- 4 and interferon- $\gamma$ by CD4 T lymphocytes. ${ }^{32}$ The chemokine SDF-1 promotes monocyte transdifferentiation to M2 polarised macrophages. ${ }^{33}$ M2-like tumour-associated macrophages help to protect cancer cells from the effect of anticancer drugs (eg, paclitaxel and cisplatin) via releasing survival signals (ie, MFG-E8, milk fat globule-EGF 8 protein), proteases (eg, cathepsins) and supporting angiogenesis by secreted factors compensating the effect of anti-VEGF therapy. ${ }^{34-36}$ CAF-derived ECM modulator proteinases, such as MMPs, FAP, urokinase-type plasminogen activators and proinflammatory cytokines (ie, IL-6 and IL-8) may also influence the relation of tumour cells to immune responses. ${ }^{32}$

\section{Practical role of CAF-derived factors in clinical oncology}

As we summarised above, CAFs are actively involved in tumourigenesis and in formation of environment-mediated drug resistance. Based on these properties of CAFs, their changed protein expression may be used as a prognostic marker. The abundance and molecular repertoire of CAFs, such as FAP, PDGF/PDGFR (platelet-derived growth factor receptor), TN-C, PDPN, secreted protein acidic and rich in cysteine, hepatocytederived growth factor receptor (HGFR, Met), TGF- $\beta$ and TGF $\beta$ Rs, carry significant prognostic information about the clinical behaviour of a given tumour (table 1).

CAFs overexpress a wide range of factors which are critical to surrounding neoplastic cell growth. Based on these features, the clinical application of these CAF-related ligands seems to be logical as the targets of anticancer therapies. One possible candidate among the CAF-derived factors is TGF- $\beta$, which acts as a suppressor of tumour formation in premalignant conditions and promotes tumour growth, invasion, angiogenesis and metastasis formation in advanced tumours ('TGF- $\beta$ Paradox'). ${ }^{57}{ }^{58}$ It has a basic role in the development of abnormal niche as a master regulator of trans-differentiation of CAFs from its precursors and with other regulators (ie, EGF, FGF and PDGF) of invasive and metastatic phenotype formation via EMT. ${ }^{59} 60$ It also influences the expression of invasion-associated proteins (including $\alpha_{\text {III }} \beta 1$ integrin and fibulin-5) as well as cellular adhesion via decreasing the expression of E-cadherin. ${ }^{61}$ By the effect of TGF- $\beta$, the fibroblasts actively produce collagen, laminin, TN and fibronectin, all of which may also contribute to a decreased cytotoxicity of anticancer agents via CAM-DR. ${ }^{10} 2062$ Upon treatment with TGF- $\beta$, mammary fibroblasts also causes an upregulation of SDF-1 chemokine, which modulates tumour cell proliferation, angiogenesis, apoptosis and antitumoural immune responses. $^{33} 6364$ TGF- $\beta$ inhibits the proliferation, differentiation and the tumour-targeting activities of natural killer (NK) and $\mathrm{T}$ cells, as well as influencing the migration of monocytes and macrophages into the tumour microenvironment. ${ }^{58} 61$ Targeted therapy against TGF- $\beta$ and its receptors includes neutralising monoclonal antibodies (mAb), antisense oligonucleotides (ASO; blocking of activation of TGF- $\beta$ ligands synthesis via inhibiting TGF- $\beta$ mRNA expression), small molecule receptor kinase inhibitors (arresting downstream canonical and noncanonical signalling by inhibiting the kinase activity of TGFßRI or TGF $\beta$ RII) are discussed in table 2.

PDGF and VEGF, basically, play a role in induction and progression of angiogenesis as well as regulation of IFP in tumour interstitium. ${ }^{29} 30$ PDGF acts as a proliferative and chemotactic factor to CAFs, as well as enhances their growth factor expression including insulin-like growth factor-1 (IGF-1), HGF, FGF and VEGF influencing tumour growth, invasion and angiogenesis. $^{8} 69$ PDGF-D ligand may cause the failure of gemcitabine treatment (via acquisition of a chemoresistant EMT phenotype)

Table 1 Function and prognostic role of CAF-related proteins

\begin{tabular}{|c|c|c|}
\hline Protein & Role in tumour biology & Disease and references \\
\hline FAP & Tumour cell growth, proliferation, ECM remodelling, metastasis formation and angiogenesis ${ }^{37}$ & DCIS, NSCLC, $\mathrm{CRC}^{38-40}$ \\
\hline PDGF/PDGFRs & Angiogenesis, regulation of interstitial fluid pressure in tumours ${ }^{41}$ & Pancreas and breast carcinoma, NSCLC ${ }^{42-44}$ \\
\hline TN-C & Hypoxia-driven angiogenesis, proliferation, migration, escape from immune surveillance ${ }^{8}$ & CRC, breast cancer, melanoma ${ }^{8}$ \\
\hline PDPN & Cancer cell invasion ${ }^{45}$ & $\begin{array}{l}\text { LACC, CRC (good prognosis) breast cancer, oesophagus } \\
\text { adenocarcinoma } 55-48\end{array}$ \\
\hline SPARC & Cell migration, proliferation, matrix cell adhesion and tissue remodelling ${ }^{49}$ & Pancreatic cancer, NSCLC ${ }^{49} 50$ \\
\hline Met & Receptor of HGF, it plays a role in the tumour cell invasion and CAF proliferation ${ }^{51}$ & $\mathrm{LACC}^{52}$ \\
\hline TGF- $\beta / T G F \beta R s$ & Tumour growth, proliferation, invasiveness, angiogenesis, immunesuppression. ${ }^{53} 54$ & CRC and breast cancer ${ }^{55} 56$ \\
\hline
\end{tabular}


Table 2 Types and clinical use of anti-TGF- $\beta /$ TGF- $\beta$ R targeted therapies

\begin{tabular}{|c|c|c|}
\hline Drug & Type, target and refs & Disease, stage and refs \\
\hline Fresolimumab/GC-1008 & $m A b$ against TGF- $\beta 1,-2,-3^{65}$ & $\begin{array}{l}\text { Breast cancer (with radiotherapy, Phase I), RCC and malignant } \\
\text { melanoma (Phase II) }{ }^{65} 66\end{array}$ \\
\hline Trabedersen/AP12009 & ASO against TGF- $\beta 1$ mRNA ${ }^{53}$ & $\begin{array}{l}\text { CRC, pancreatic carcinoma and malignant melanoma, NSCLC } \\
(\text { Phase } 1 / I / I)^{53}\end{array}$ \\
\hline $\begin{array}{l}\text { Belagenpumatucel-L/ } \\
\text { Lucanix; }\end{array}$ & $\begin{array}{l}\text { ASO (antisense gene-modified allogeneic tumour cell vaccine) against } \\
\text { TGF- } \beta 2 \text { mRNA }^{53} 66\end{array}$ & NSCLC (Phase II) ${ }^{67}$ \\
\hline LY2157299 & TGF $\beta$ R1 serine/threonine kinase inhibitor ${ }^{68}$ & HCC (Phase II), pancreatic cancer (with gemcitabine, Phase I/II) ${ }^{66} 68$ \\
\hline
\end{tabular}

of hepatocellular carcinoma (HCC) cells; furthermore, PDGF-C mediates resistance to antiangiogenic therapy with VEGF inhibitors. ${ }^{43}$ VEGF influences tumour perfusion, vascular volume, permeability activity, microvascular density and the number of circulating endothelial and progenitor cells. ${ }^{30} 71$ VEGF/VEGFR (vascular endothelial growth factor receptor) signalling protects endothelial, ovarian and NSCLC cells against chemotherapeutic injury via the activation of PI3K/AKT pathway and induction of antiapoptotic proteins including Bcl-2 and survivin. ${ }^{20} 72-74$ Inhibition of PDGFRs and VEGFRs by multikinase inhibitors and anti-VEGF mAbs seems to be effective anticancer strategies (table 3).

Carcinoma cells induce HGF secretion of CAFs by different regulator secretion, such as IL-1 $\beta$, bFGF, PGE 2 , PDGF and TGF- $\beta .^{8}{ }^{84}$ CAF-secreted HGF signal influences the invasion of transformed epithelial cells (including enhanced dissociation and stromal migration of cancer cells) and stimulates CAF proliferation as autocrine loop via Met-tyrosine kinase receptor activation. $^{515285}$ HGF protects cancer cells from chemotherapeutic agents via enhancing DNA repair by reactivation of Met/PI3K/ extracellular-signal-regulated kinase (ERK) cascades and downregulation of the expression of antiapoptotic proteins (ie, $\mathrm{Bcl}-\mathrm{XL}) .{ }^{86}{ }^{87} \mathrm{HGF}$ is also involved in the mechanisms of resistance development to BRAF and human epidermal growth factor receptor 2 inhibitors as well as selective EGFR- tyrosine kinase inhibitors (TKIs) (ie, gefitinib and erlotinib). ${ }^{288} 89$ It is a chemotactic factor for $\mathrm{T}$ cells and a negative regulator of the cytotoxic activity of NK cells furthermore modulates the immunoglubulin production and maturation of B-cells. ${ }^{32}$ In table 4 , we summarise the most important HGF $\mathrm{mAbs}$ and selective/non-selective Met-TKIs.
Stromal IGF-1 increases the invasive capacity of cancer cells, influences the proliferation of epithelial cells (via upregulation of mitogen-activated protein kinase (MAPK)/AKT, Cyclin D1 and downregulation of $\mathrm{p} 27$ ) and upregulates the proliferationassociated genes in stromal fibroblasts. ${ }^{107} 108$ IGF-1/IGF-1R signal mediates the therapeutic response to conventional chemotherapeutic agents, such as 5-fluorouracil and gemcitabine, through increased survivin stability. ${ }^{109} 110$ CAFs secreted IGF-2 also can influence the survival of cancer cells induced via acquisition of stem cell-like properties. ${ }^{111}$ Blocking of IGF signalling with anti-IGF-1R mAbs, such as AMG 479, B11B022 and cixutumumab/IMC-A12 together with IGF-1R kinase inhibitors (eg, AXL 1717, BMS-754807 and linsitinib/OSI-906) proved clinical benefit in the treatment of HCC, SCLC, NSCLC, breast and pancreatic cancers (phase I/II stage). ${ }^{8}$

FAP/F19 belonging to the family of plasma membrane-bound serine proteases promoting tumour cell growth and proliferation plays a role in ECM remodelling (ie, degrading type I collagen and influencing MMPs' expression), metastasis formation, angiogenesis and deregulation of antitumoural immune responses. ${ }^{112}$ The use of humanised mAb F19 (sibrotuzumab) and small-molecule FAP enzyme-inhibitor (talabostat) showed no therapeutical benefits alone or in combination in case of metastatic colorectal carcinoma, NSCLC, stage IV melanoma and chronic lymphocytic leukaemia. ${ }^{112} 113$ FAP-based target therapies were found to be promising in preclinical studies, such as doxorubicin-combined FAP-targeting prodrugs and DNA vaccines. ${ }^{114} 115$ FAP radioimmunotherapy (targeted delivery of therapeutic radioisotopes to the tumour site by the developed sensitive FAP mAbs) and short heparin RNA vectorbased therapies (RNA inteterference) also seems to be a promising anticancer treatment in the future. ${ }^{116} 117$

Table 3 Types and clinical use of anti-VEGF mAbs and multi-kinase inhibitors

\begin{tabular}{|c|c|c|}
\hline Drug & Type and target & Disease, stage and references \\
\hline Avastin/Bevacizumab & mAb against VEGF ${ }^{75}$ & Multiple tumour types including: CRC, NSCLC, and breast cancer (FDA app) \\
\hline $\begin{array}{l}\text { Pazopanib/ } \\
\text { GW786034 }\end{array}$ & $\begin{array}{l}\text { TKI of VEGFR-1,-2,-3, PDGFR } \alpha,-\beta, \text { Kit, FGFR-1,-3, Itk, Lek, } \\
\text { c-Fms }{ }^{76}\end{array}$ & $\begin{array}{l}\text { Multiple tumour types including: solid tumours (with paclitaxel/carboplatin, Phase I), } \\
\text { RCC (FDA app) }\end{array}$ \\
\hline Imatinib/STI157 & TKI of PDGFR $\beta$,Bcr-Abl, $\mathrm{Kit}^{78}$ & Multiple tumour types including: GIST (FDA app) ${ }^{78}$ \\
\hline Sunitinib/SU11248 & TKI of VEGFR1-,2,-3, PDGFR $\alpha,-\beta$, Kit, FLT-3, CSF1R, RET ${ }^{78}$ & GIST (imatinib resist; FDA app), RCC (FDA app), NSCLC (Phase III) ${ }^{78} 79$ \\
\hline Motesanib & TKI of VEGFR1,-2, PDGFR $\beta$, Kit, RET ${ }^{80}$ & $\begin{array}{l}\text { NSCLC (with carboplatin/paclitaxel, Phase III), breast cancer (with docetaxel/paclitaxel, } \\
\text { Phase I/II) }\end{array}$ \\
\hline Sorafenib & TKI of VEGFR2,-3, PDGFR $\beta$ Kit, RET, B-Raf, FLT-3 ${ }^{78} 83$ & Multiple tumour types including: RCC (FDA app), HCC (FDA app) ${ }^{83}$ \\
\hline
\end{tabular}


Table 4 Types and clinical use of anti-HGF mAbs and multi-kinase inhibitors

\begin{tabular}{|c|c|c|}
\hline Drug & Type, target and references & Disease, stage and references \\
\hline Ficlatuzumab/AV-299 & $\mathrm{mAb}$ against $\mathrm{HGF}^{90}$ & Solid tumours (Phase I/II), NSCLC (combined with gefitinib, Phase II). ${ }^{90}$ \\
\hline Rilotumumab/AMG 102 & mAb against $\mathrm{HGF}^{90}$ & $\begin{array}{l}\text { Multiple tumour types including: RCC (Phase II), prostate cancer (combined with mitoxantrone } \\
\text { and } \\
\text { prednisone, Phase II). }{ }^{91}{ }^{92}\end{array}$ \\
\hline Onartuzumab/PR0143966 & $\mathrm{mAb}$ against $\mathrm{Met}^{93}$ & NSCLC (combination with erlotinib, Phase II), solid tumours (Phase I) ${ }^{94} 95$ \\
\hline $\begin{array}{l}\text { Cabozantinib/ } \\
\text { BMS-907351 }\end{array}$ & $\begin{array}{l}\text { TKI of Met, VEGFR2, RET, Kit, AXL and } \\
\text { FLT3 }^{96}\end{array}$ & Multiple tumour types including: prostate, breast cancer, NSCLC (Phase II) ${ }^{9798}$ \\
\hline Crizotinib/PF-02341066 & TKI of Met, ALK and ROS1 ${ }^{99}$ & NSCLC (Phase III), GEC (Phase I) ${ }^{99} 100$ \\
\hline Tivantinib/ARQ 197 & TKI of Met ${ }^{101}$ & HCC (Phase II), NSCLC (Phase II), gastric cancer (Phase II) ${ }^{102-104}$ \\
\hline Foretinib/GSK1363089 & TKI of Met, VEGFR2, RON, Kit and AXL ${ }^{105}$ & Gastric cancer (Phase II), solid tumours (Phase I) ${ }^{105} 106$ \\
\hline
\end{tabular}

ALK, anaplastic lymphoma kinase; FLT3, FMS-like tyrosine kinase-3; GEC, gastroesophageal cancer; HCC, hepatocellular carcinoma; HGF, hepatocyte growth factor; NSCLC, non-small cell lung cancer; RCC, renal cell carcinoma; RON, Recepteur d'Origine Nantais; VEGFR, vascular endothelial growth factor receptor; mAb, monoclonal antibody; TKI, tyrosine kinase inhibitors; RET, rearranged during transfection; ROS1, c-ros oncogene 1; Met, hepatocyte-derived growth factor receptor.

\section{CONCLUSION}

CAF-induced signalling pathways function as key factors in stroma-supported cancer progression, and can be therapeutically targeted against microenvironment-mediated drug resistance. Focusing the attention on these microenvironmental cells may help us to better understand their role in tumour pathogenesis and, moreover, may help to better predict the clinical outcome of disease, and to make patient-tailored anticancer treatments.

\section{Take home messages}

- CAF-derived factors may provide pro-tumorigenic effects via altering the tumorous microenvironment.

- Targeting CAF-derived factors may act as potential anticancer therapeutic strategies.

- CAF-derived factors may be clinically used as prognostic factors of different tumorous diseases.

Contributors GV: wrote the manuscript; FS, ZT, BM, YY: corrected and made critical review of the manuscript.

Competing interests None.

Provenance and peer review Not commissioned; externally peer reviewed.

Correction notice A sentence under the section 'Practical role of CAF-derived factors in clinical oncology' has been corrected since published Online First.

\section{REFERENCES}

1 Shimoda M, Mellody KT, Orimo A. Carcinoma-associated fibroblasts are a rate-limiting determinant for tumour progression. Semin Cell Dev Biol 2010:21:19-25

2 Olson OC, Joyce JA. Microenvironment-mediated resistance to anticancer therapies. Cell Res 2013;23:179-81.

3 Swartz MA, lida N, Roberts EW, et al. Tumor microenvironment complexity: emerging roles in cancer therapy. Cancer Res 2012;72:2473-80.

4 Hinz B, Phan SH, Thannickal VJ, et al. Recent developments in myofibroblast biology: paradigms for connective tissue remodeling. Am J Pathol 2012;180:1340-55

5 Kahlert C, Kalluri R. Exosomes in tumor microenvironment influence cancer progression and metastasis. J Mol Med 2013;91:431-7.

6 Mitra AK, Zillhardt M, Hua Y, et al. MicroRNAs reprogram normal fibroblasts into cancer-associated fibroblasts in ovarian cancer. Cancer Discov 2012:2:1100-8.

7 Sabbah M, Emami S, Redeuilh G, et al. Molecular signature and therapeutic perspective of the epithelial-to-mesenchymal transitions in epithelial cancers. Drug Resist Updat 2008:11:123-51.

8 Takebe N, Ivy P, Timmer W, et al. Review of cancer-associated fibroblasts and therapies that interfere with their activity. Tum Microenvir and Ther 2013;1:19-36.

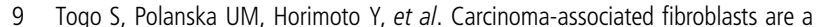
promising therapeutic target. Cancers 2013;5:149-69.

10 Paraiso KH, Smalley KS. Fibroblast-mediated drug resistance in cancer. Biochem Pharmacol 2013;85:1033-41.

11 Bremnes RM, Dønnem T, Al-Saad S, et al. The role of tumor stroma in cance progression and prognosis: emphasis on carcinoma-associated fibroblasts and non-small cell lung cancer. J Thorac Oncol 2011:6:209-17.

12 Gonda TA, Varro A, Wang TC, et al. Molecular biology of cancer-associated fibroblasts: can these cells be targeted in anti-cancer therapy? Semin Cell Dev Biol 2010:21:2-10.

13 Moinfar F, Man YG, Arnould L, et al. Concurrent and independent genetic alterations in the stromal and epithelial cells of mammary carcinoma: implications for tumorigenesis. Cancer Res 2000;60:2562-6.

14 Kurose K, Gilley K, Matsumoto S, et al. Frequent somatic mutations in PTEN and TP53 are mutually exclusive in the stroma of breast carcinomas. Nat Gen 2002:32:355-7.

15 Patocs $A$, Zhang $L, X u$ Y, et al. Breast-cancer stromal cells with TP53 mutations and nodal metastases. N Engl J Med 2007;357:2543-51.

16 Wernert N, Löcherbach C, Wellmann A, et al. Presence of genetic alterations in microdissected stroma of human colon and breast cancers. J Mol Med 2000;78: B30.

17 Campbell I, Polyak K, Haviv I. Clonal mutations in the cancer-associated fibroblasts: the case against genetic coevolution. Cancer Res 2009;69: 6765-8

18 Hosein AN, Wu M, Arcand SL, et al. Breast carcinoma-associated fibroblasts rarely contain p53 mutations or chromosomal aberrations. Cancer Res 2010:70:5770-7.

19 Qiu W, Hu M, Sridhar A, et al. No evidence of clonal somatic genetic alterations in cancer-associated fibroblasts from human breast and ovarian carcinomas. Nat Gen 2008:40:650-5.

20 Castells M, Thibault B, Delord JP, et al. Implication of tumor microenvironment in chemoresistance: tumor-associated stromal cells protect tumor cells from cell death. Int J Mol Sci 2012;13:9545-71.

21 Meads MB, Gatenby RA, Dalton WS. Environment-mediated drug resistance: a major contributor to minimal residual disease. Nat Rev Cancer 2009;9:665-74.

22 Li G, Satyamoorthy K, Herlyn M. N-cadherin-mediated intercellular interactions promote survival and migration of melanoma cells. Cancer Res 2001:61:3819-25.

23 Choe C, Shin YS, Kim SH, et al. Tumor-stromal interactions with direct cell contacts enhance motility of non-small cell lung cancer cells through the hedgehog signaling pathway. Anticancer Res 2013:33:3715-23.

24 Sarkar FH, Li Y, Wang Z, et al. Pancreatic cancer stem cells and EMT in drug resistance and metastasis. Minerva Chir 2009;64:489-500.

25 Wu Q, Wang R, Yang Q, et al. Chemoresistance to gemcitabine in hepatoma cells induces epithelial-mesenchymal transition and involves activation of PDGF-D pathway. Oncotarget 2013;4:1999-2009.

26 Aoudjit F, Vuori K. Integrin signaling in cancer cell survival and chemoresistance. Chemother Res Pract 2012;2012:283181.

27 Ruan K, Bao S, Ouyang G. The multifaceted role of periostin in tumorigenesis Cell Mol Life Sci 2009:66:2219-30.

28 Sun Y, Campisi J, Higano C, et al. Treatment-induced damage to the tumor microenvironment promotes prostate cancer therapy resistance through WNT16B. Nat Med 2012;18:1359-68.

29 Kłosowska-Wardega A, Hasumi Y, Burmakin M, et al. Combined anti-angiogenic therapy targeting PDGF and VEGF receptors lowers the interstitial fluid pressure in a murine experimental carcinoma. PLOS ONE 2009:4:e8149. 
30 Willett CG, Boucher Y, di Tomaso E, et al. Direct evidence that the VEGF-specific antibody bevacizumab has antivascular effects in human rectal cancer. Nat Med 2004:10:145-7.

31 Zhang J, Liu J. Tumor stroma as targets for cancer therapy. Pharmacol Ther 2013:137:200-15.

32 Silzle T, Randolph GJ, Kreutz M, et al. The fibroblast: sentinel cell and local immune modulator in tumor tissue. Int I Cancer 2004:108:173-80.

33 Comito G, Giannoni E, Segura CP, et al. Cancer-associated fibroblasts and M2-polarized macrophages synergize during prostate carcinoma progression. Oncogene 2014;33:2423-31.

34 De Palma M, Lewis CE. Macrophage regulation of tumor responses to anticancer therapies. Cancer Cell 2013:23:277-86.

35 Junttila MR, de Sauvage FJ. Influence of tumour micro-environment heterogeneity on therapeutic response. Nature 2013:501:346-54.

36 Shree T, Olson OC, Elie BT, et al. Macrophages and cathepsin proteases blunt chemotherapeutic response in breast cancer. Genes Dev 2011:25:2465-79.

37 Liu R, Li H, Liu L, et al. Fibroblast activation protein: a potential therapeutic target in cancer. Cancer Biol Ther 2012:13:123-9.

38 Hua $X$, Yu L, Huang $X$, et al. Expression and role of fibroblast activation protein-alpha in microinvasive breast carcinoma. Diagn Pathol 2011;6:111.

39 Liao Y, Ni Y, He R, et al. Clinical implications of fibroblast activation protein- $\alpha$ in non-small cell lung cancer after curative resection: a new predictor for prognosis. J Cancer Res Clin Oncol 2013;139:1523-8.

40 Wikberg ML, Edin S, Lundberg IV, et al. High intratumoral expression of fibroblast activation protein (FAP) in colon cancer is associated with poorer patient prognosis. Tumor Biol 2013;34:1013-20.

41 Pietras K, Rubin K, Sjöblom T, et al. Inhibition of PDGF receptor signaling in tumor stroma enhances antitumor effect of chemotherapy. Cancer Res 2002:62:5476-84

42 Yuzawa S, Kano MR, Einama T, et al. PDGFR $\beta$ expression in tumor stroma of pancreatic adenocarcinoma as a reliable prognostic marker. Med Onc 2012;29:2824-30

43 Paulsson J, Sjöblom T, Micke P, et al. Prognostic significance of stroma platelet-derived growth factor beta-receptor expression in human breast cancer. Am J Pathol 2009:175:334-41.

44 Donnem T, Al-Saad S, Al-Shibli K, et al. Prognostic impact of platelet-derived growth factors in non-small cell lung cancer tumor and stromal cells. J Thorac Oncol 2008:3:963-70.

45 Shindo K, Aishima S, Ohuchida K, et al. Podoplanin expression in cancer-associated fibroblasts enhances tumor progression of invasive ductal carcinoma of the pancreas. Mol Cancer 2013;12:168.

46 Ito $\mathrm{M}$, Ishii $\mathrm{G}$, Nagai $\mathrm{K}$, et al. Prognostic impact of cancer-associated stromal cells in patients with stage I lung adenocarcinoma. Chest 2012;142:151-8.

47 Yamanashi T, Nakanishi Y, Fujii G, et al. Podoplanin expression identified in stromal fibroblasts as a favorable prognostic marker in patients with colorectal carcinoma. Oncology 2009;77:53-62.

48 Schoppmann SF, Jesch B, Riegler MF, et al. Podoplanin expressing cancer associated fibroblasts are associated with unfavourable prognosis in adenocarcinoma of the esophagus. Clin Exp Metastasis 2013;30:441-6.

49 Infante JR, Matsubayashi $\mathrm{H}$, Sato N, et al. Peritumoral fibroblast SPARC expression and patient outcome with resectable pancreatic adenocarcinoma. J Clin Oncol 2007;25:319-25

50 Koukourakis MI, Giatromanolaki A, Brekken RA, et al. Enhanced expression of SPARC/osteonectin in the tumor-associated stroma of non-small cell lung cancer is correlated with markers of hypoxia/acidity and with poor prognosis of patients. Cancer Res 2003;63:5376-80.

51 Matsumoto K, Nakamura T. Hepatocyte growth factor and the Met system as a mediator of tumor-stromal interactions. Int I Cancer 2006;119:477-83.

52 Tokunou M, Niki T, Eguchi $\mathrm{K}$, et al. c-MET expression in myofibroblasts: role in autocrine activation and prognostic significance in lung adenocarcinoma. Am J Pathol 2001;158:1451-63.

53 Calon A, Tauriello DV, Batlle E. TGF-beta in CAF-mediated tumor growth and metastasis. Semin Cancer Biol 2014;25:15-22.

54 Connolly EC, Freimuth J, Akhurst RJ. Complexities of TGF- $\beta$ targeted cancer therapy. Int J Biol Sci 2012;8:964-78.

55 Robson $\mathrm{H}$, Anderson $\mathrm{E}$, James RD, et al. Transforming growth factor beta 1 expression in human colorectal tumours: an independent prognostic marker in a subgroup of poor prognosis patients. Br J Cancer 1996;74:753-8.

56 Busch S, Acar A, Magnusson Y, et al. TGF-beta receptor type-2 expression in cancer-associated fibroblasts regulates breast cancer cell growth and survival and is a prognostic marker in pre-menopausal breast cancer. Oncogene Published Online First: 16 Dec 2013. doi:10.1038/onc.2013.527

57 Kakarla S, Song XT, Gottschalk S. Cancer-associated fibroblasts as targets for immunotherapy. Immunotherapy 2012:4:1129-38.

58 Tian M, Schiemann WP. The TGF- $\beta$ paradox in human cancer: an update. Future Oncol 2009:5:259-71.
59 Cirri P, Chiarugi P. Cancer associated fibroblasts: the dark side of the coin. Am J Cancer Res 2011;1:482-97.

60 Xu J, Lamouille S, Derynck R. TGF-beta-induced epithelial to mesenchyma transition. Cell Res 2009;19:156-72.

61 Elliott RL, Blobe GC. Role of transforming growth factor Beta in human cancer. J Clin Oncol 2005;23:2078-93.

62 Berking C, Takemoto R, Schaider H, et al. Transforming growth factor-beta1 increases survival of human melanoma through stroma remodeling. Cancer Res 2001;61:8306-16.

63 Kojima Y, Acar A, Eaton EN, et al. Autocrine TGF-beta and stromal cell-derived factor-1 (SDF-1) signaling drives the evolution of tumor-promoting mammary stromal myofibroblasts. Proc Natl Acad Sci USA 2010;107:20009-14.

64 Kryczek I, Wei S, Keller E, et al. Stroma-derived factor (SDF-1/CXCL12) and human tumor pathogenesis. Am J Physiol Cell Physiol 2007:292:987-95.

65 Morris JC, Tan AR, Olencki TE, et al. Phase i study of GC1008 (Fresolimumab): a human anti-transforming growth factor-beta (TGF $\beta$ ) monoclonal antibody in patients with advanced malignant melanoma or renal cell carcinoma. PLOS ONE 2014;9:e90353.

66 Smith AL, Robin TP, Ford HL. Molecular pathways: targeting the TGF- $\beta$ pathway for cancer therapy. Clin Cancer Res 2012;18:4514-21.

67 Nemunaitis J, Nemunaitis M, Senzer N, et al. Phase II trial of Belagenpumatucel-L, a TGF-beta2 antisense gene modified allogeneic tumor vaccine in advanced non small cell lung cancer (NSCLC) patients. Cancer Gene Ther 2009:16:620-4.

68 Giannelli G, Villa E, Lahn M. Transforming growth factor- $\beta$ as a therapeutic target in hepatocellular carcinoma. Cancer Res 2014:74:1890-94.

69 Dong J, Grunstein J, Tejada M, et al. VEGF-null cells require PDGFR alpha signaling-mediated stromal fibroblast recruitment for tumorigenesis. EMBO J 2004:23:2800-10.

70 Crawford Y, Kasman I, Yu L, et al. PDGF-C mediates the angiogenic and tumorigenic properties of fibroblasts associated with tumors refractory to anti-VEGF treatment. Cancer Cell 2009;15:21-34.

71 Li X, Ma Q, Xu Q, et al. Targeting the cancer-stroma interaction: a potentia approach for pancreatic cancer treatment. Curr Pharm Des 2012;18:2404-15.

72 Tran J, Master Z, Yu JL, et al. A role for survivin in chemoresistance of endothelia cells mediated by VEGF. Proc Natl Acad Sci USA 2002;99:4349-54.

73 Hu G, Ryan S, Zhu Y, et al. Vascular endothelial growth factor modulates cisplatin sensitivity in human ovarian carcinoma cells. Cancer Ther 2003;1:31-7.

74 Yang $F$, Tang $X$, Riquelme $E$, et al. Increased VEGFR-2 gene copy is associated with chemoresistance and shorter survival in patients with non-small-cell lung carcinoma who receive adjuvant chemotherapy. Cancer Res 2011;71:5512-21.

75 Ferrara N, Hillan KJ, Gerber HP, et al. Discovery and development of bevacizumab, an anti-VEGF antibody for treating cancer. Nat Rev Drug Disc 2004;3:391-400.

76 van Geel RM, Beijnen JH, Schellens JH. Concise drug review: pazopanib and axitinib. Oncologist 2012;17:1081-89.

77 Burris HA, Dowlati A, Moss RA, et al. Phase I study of pazopanib in combination with paclitaxel and carboplatin given every 21 days in patients with advanced solid tumors. Mol Cancer Ther 2012;11:1820-8.

78 Broekman F, Giovannetti E, Peters GJ. Tyrosine kinase inhibitors: Multi-targeted or single-targeted? World I Clin Oncol 2011:2:80-93.

79 Rock EP, Goodman V, Jiang JX, et al. Food and Drug Administration drug approval summary: Sunitinib malate for the treatment of gastrointestinal stromal tumor and advanced renal cell carcinoma. Oncologist 2007;12:107-13.

80 De Boer RH, Kotasek D, White S, et al. Phase $1 \mathrm{~b}$ dose-finding study of motesanib with docetaxel or paclitaxel in patients with metastatic breast cancer. Breast Cancer Res Treat 2012;135:241-52.

81 Scagliotti GV, Vynnychenko I, Park K, et al. International, randomized, placebo-controlled, double-blind phase III study of motesanib plus carboplatin/ paclitaxel in patients with advanced nonsquamous non-small-cell lung cancer: MONET1. J Clin Oncol 2012;30:2829-36.

82 Martin $\mathrm{M}$, Roche $\mathrm{H}$, Pinter T, et al. Motesanib, or open-label bevacizumab, in combination with paclitaxel, as first-line treatment for HER2-negative locally recurrent or metastatic breast cancer: a phase 2, randomised, double-blind, placebo-controlled study. Lancet Oncol 2011;12:369-76.

83 Wilhelm SM, Adnane L, Newell P, et al. Preclinical overview of sorafenib, a multikinase inhibitor that targets both Raf and VEGF and PDGF receptor tyrosine kinase signaling. Mol Cancer Ther 2008;7:3129-40.

84 Matsumoto K, Nakamura T, Sakai K, et al. Hepatocyte growth factor and Met in tumor biology and therapeutic approach with NK4. Proteomics 2008;8:3360-70.

85 Grugan KD, Miller CG, Yao Y, et al. Fibroblast-secreted hepatocyte growth factor plays a functional role in esophageal squamous cell carcinoma invasion. Proc Nat Acad Sci USA 2010;107:11026-31.

86 Mizuno S, Nakamura T. HGF-MET Cascade, a Key Target for Inhibiting Cancer Metastasis: The Impact of NK4 Discovery on Cancer Biology and Therapeutics. Int I Mol Sci 2013:14:888-919.

87 Fan S, Wang JA, Yuan RQ, et al. Scatter factor protects epithelial and carcinoma cells against apoptosis induced by DNA-damaging agents. Oncogene 1998:17:131-41. 
88 Straussman R, Morikawa T, Shee K, et al. Tumour micro-environment elicits innate resistance to RAF inhibitors through HGF secretion. Nature 2012;487:500-4.

89 Wang W, Li Q, Yamada T, et al. Crosstalk to stromal fibroblasts induces resistance of lung cancer to epidermal growth factor receptor tyrosine kinase inhibitors. Clin Cancer Res 2009:15:6630-8.

90 Peters S, Adjei AA. MET: a promising anticancer therapeutic target. Nat Rev Clin Oncol 2012:9:314-26.

91 Schöffski P, Garcia JA, Stadler WM, et al. A phase II study of the efficacy and safety of AMG 102 in patients with metastatic renal cell carcinoma. BJU Int 2011;108:679-86.

92 Ryan CJ, Rosenthal M, Ng S, et al. Targeted MET inhibition in castration-resistant prostate cancer: a randomized phase II study and biomarker analysis with rilotumumab plus mitoxantrone and prednisone. Clin Cancer Res 2013;19:215-24.

93 Bendell JC, Ervin TJ, Gallinson D, et al. Treatment rationale and study design for a randomized, double-blind, placebo-controlled phase II study evaluating onartuzumab (MetMAb) in combination with bevacizumab plus mFOLFOX-6 in patients with previously untreated metastatic colorectal cancer. Clin Colorectal Cancer 2013;12:218-22

94 Spigel DR, Ervin TJ, Ramlau RA, et al. Randomized phase II trial of onartuzumab in combination with erlotinib in patients with advanced non-small-cell lung cancer. J Clin Oncol 2013:31:4105-14.

95 Salgia R, Patel P, Bothos J, et al. Phase I dose-escalation study of onartuzumab as a single agent and in combination with bevacizumab in patients with advanced solid malignancies. Clin Cancer Res 2014;20:1666-75.

96 Yakes FM, Chen J, Tan J, et al. Cabozantinib (XL184), a novel MET and VEGFR2 inhibitor, simultaneously suppresses metastasis, angiogenesis, and tumor growth. Mol Cancer Ther 2011;10:2298-308.

97 Smith DC, Smith MR, Sweeney C, et al. Cabozantinib in patients with advanced prostate cancer: results of a phase II randomized discontinuation trial. J Clin Oncol 2013;31:412-19.

98 Gherardi E, Birchmeier W, Birchmeier C, et al. Targeting MET in cancer: rationale and progress. Nat Rev Cancer 2012;12:89-103.

99 Shaw AT, Kim DW, Nakagawa K, et al. Crizotinib versus chemotherapy in advanced ALK-positive lung cancer. N Engl J Med 2013;368:2385-94.

100 Lennerz JK, Kwak FL, Ackerman A, et al. MET amplification identifies a small and aggressive subgroup of esophagogastric adenocarcinoma with evidence of responsiveness to crizotinib. J Clin Oncol 2011;29:4803-10.

101 Munshi N, Jeay S, Li Y, et al. ARQ 197, a novel and selective inhibitor of the human c-Met receptor tyrosine kinase with antitumor activity. Mol Cancer Ther 2010;9:1544-53.

102 Santoro A, Rimassa L, Borbath I, et al. Tivantinib for second-line treatment of advanced hepatocellular carcinoma: a randomised, placebo-controlled phase 2 study. Lancet Oncol 2013;14:55-63.
103 Kang YK, Muro K, Ryu MH, et al. A phase II trial of a selective c-Met inhibitor tivantinib (ARQ 197) monotherapy as a second- or third-line therapy in the patients with metastatic gastric cancer. Invest New Drugs 2014;32:355-61.

104 Sequist LV, von Pawel J, Garmey EG, et al. Randomized phase II study of erlotinib plus tivantinib versus erlotinib plus placebo in previously treated non-small-cell lung cancer. J Clin Oncol 2011;29:3307-15.

105 Shapiro GI, McCallum S, Adams LM, et al. A Phase 1 dose-escalation study of the safety and pharmacokinetics of once-daily oral foretinib, a multi-kinase inhibitor, in patients with solid tumors. Invest New Drugs 2013;31:742-50.

106 Shah MA, Wainberg ZA, Catenacci DV, et al. Phase II study evaluating 2 dosing schedules of oral foretinib (GSK1363089), cMET/VEGFR2 inhibitor, in patients with metastatic gastric cancer. PLoS One 2013;8:e54014.

107 Franco OE, Shaw AK, Strand DW, et al. Cancer associated fibroblasts in cance pathogenesis. Semin Cell Dev Biol 2010;21:33-9.

108 Rajski M, Zanetti-Dällenbach R, Vogel B, et al. IGF-I induced genes in stromal fibroblasts predict the clinical outcome of breast and lung cancer patients. $B M C$ Med 2010;8:1

109 Juan HC, Tsai HT, Chang PH, et al. Insulin-like growth factor 1 mediates 5 -fluorouracil chemoresistance in esophageal carcinoma cells through increasing survivin stability. Apoptosis 2011;16:174-83.

110 Kawanami T, Takiguchi S, Ikeda N, et al. A humanized anti-IGF-1R monoclonal antibody (R1507) and/or metformin enhance gemcitabine-induced apoptosis in pancreatic cancer cells. Oncol Rep 2012;27:867-72.

111 Chen WJ, Ho CC, Chang YL, et al. Cancer-associated fibroblasts regulate the plasticity of lung cancer stemness via paracrine signaling. Nat Commun 2014;5:3472.

112 Xing F, Saidou J, Watabe K. Cancer associated fibroblasts (CAFs) in tumor microenvironment. Front Biosci 2010;15:166-79.

113 Brennen WN, Isaacs JT, Denmeade SR. Rationale behind targeting fibroblast activation protein-expressing carcinoma-associated fibroblasts as a novel chemotherapeutic strategy. Mol Cancer Ther 2012;11:257-66.

114 Loeffler M, Krüger JA, Niethammer AG, et al. Targeting tumor-associated fibroblasts improves cancer chemotherapy by increasing intratumoral drug uptake. J Clin Invest 2006;116:1955-62.

115 Huang S, Fang R, Xu J, et al. Evaluation of the tumor targeting of a FAP $\alpha$-based doxorubicin prodrug. J Drug Target 2011;19:487-96.

116 Fischer E, Chaitanya K, Wüest T, et al. Radioimmunotherapy of fibroblast activation protein positive tumors by rapidly internalizing antibodies. Clin Cancer Res 2012;18:6208-18.

117 Cai F, Li Z, Wang C, et al. Short hairpin RNA targeting of fibroblast activation protein inhibits tumor growth and improves the tumor microenvironment in a mouse model. BMB Rep 2013:46:252-7. 